\title{
The most cited articles on the topic of health behaviors in Google Trends research: a systematic review
}

\author{
Wei Chih Kan ${ }^{1,2}$ Tsair Wei Chien ${ }^{3}$ Hsien Yi Wang ${ }^{1,4}$ Willy Chou ${ }^{5,6^{*}}$
}

\begin{abstract}
Background: Over the past decade, the use of Web-based data in public health issues has been proven useful in assessing various aspects of human behavior. Google Trends is the most popular tool to gather such information and has been applied to several topics with the most focused subject related to health and medicine. However, the most cited articles and the popular medical subject headings (MESH terms) on health behaviors in Google Trends research remain unknown. The web-based behavior requires to monitor and analyze on-line data for examining actual human behavior to predict and even prevent health-related issues that constantly arise in daily life. Objective: This systematic review aimed at reporting and further presenting the most cited articles and the popular MESH terms on health behaviors in Google Trends (infodemiology) researches in health-related topics since 2009 to provide an overview of the topic burst for future research on the subject of health behavior. Methods: Following the Meta-Analyses guidelines for selecting studies, we searched for the term "Google Trends [Title]" in PubMed databases since 2009, applying specific criteria for types of journal articles. A total of 86 published papers were extracted, excluding those that did not fall inside the topics of health and medicine or the selected article types. We then further categorized the published papers according to MESH terms using social network analysis (SNA) and selected the most cited articles that related to the health behavior in Google Trends. Results: The most cited articles are those from the US in 2009 ( $\mathrm{PMID}=19845471$ cited 88 times) and the UK in 2013 (PMID= 23619126 cited 74 times). The MESH term represented by Internet earns the highest impact factor (IF) and presents significantly different among term clusters $(\mathrm{F}(3,20)=15.79, \mathrm{p}<0.001)$. The most number of citing journals is from PloS One. The most number of author affiliations is from the US. Conclusion: The monitoring of online queries can provide insight into human behavior, as the phenomenon is significantly and continuously growing at present and in the future for assessing behavioral changes in health topics.
\end{abstract} analysis

Keywords: health behavior, infodemiology, Google Trends, medical subject headings, social network

\section{Introduction}

Big data are characterized by the eight $\mathrm{Vs}^{[1-5]}$ (i.e., volume, variety, velocity, veracity, value, variability, volatil-

\footnotetext{
Received: November 8, 2018 Accepted: December 8, 2018 Published: December 17, 2018

* Correspondence to: Willy Chou, Chi Mei Medical Center, 901 Chung Hwa Road, Yung Kung Dist., Tainan 710, Taiwan; Email: ufan0101@ms22.hinet.net

${ }^{1}$ Department of Nephrology, Chi-Mei Medical Center, Tainan, Taiwan

2 Department of Biological Science and Technology, Chung Hwa University of Medical Technology, Tainan, Taiwan

${ }^{3}$ Medical Research Department, Chi-Mei Medical Center, Tainan, Taiwan

${ }^{4}$ Department of Sport Management, College of Leisure and Recreation Management, Chia Nan University of Pharmacy and Science, Tainan, Taiwan

${ }^{5}$ Department of physical medicine and rehabilitation, Chi Mei medical center, Tainan,

Taiwan
6 Department of Recreation and Health-Care Management Institute of recreation Industry Management, Chia Nan University of Pharmacy, Tainan, Taiwan

Citation: Kan WC, Chien TW, Wang HY, et al. The most cited articles on the topic of health behaviors in Google Trends research: a systematic review. Adv Gen Pract Med, 2018, 2(1): 1-7

Copyright: (c) 2018 Willy Chou, et al. This is an open access article distributed under the terms of the Creative Commons Attribution License, which permits unrestricted use, distribution, and reproduction in any medium, provided the original author and source are credited.
}

ity, and validity and have shown great potential in forecasting and better decision making. Handling these data with conventional ways is inadequate ${ }^{[6]}$ and hence requires novel approaches and methods applied to healthcare research. ${ }^{[7]}$

The online search queries have been popular in big data analytics for academic research. ${ }^{[8,9]}$ The use of search traffic data from web-based sources can assist in facilitating a better understanding the Web-based behavior and behavioral changes. ${ }^{[10]}$ Online search traffic data have been deemed as a good analyzer of internet behavior, while Google Trends ${ }^{[11]}$ acts as a reliable tool in predicting changes in human behavior and as an accurate measure which is the publics interest. ${ }^{[12]}$ What are the most popular topics in health behavior using Google Trends remain unknown. The monitoring of web-based activity (or health behavior) can be thus a valid indicator of public behavior. ${ }^{[13]}$ 
Healthcare is one of the top fields to which big data are widely applied ${ }^{[14,15]}$ with many publications showing a high increase. ${ }^{[16]}$ Researchers have also placed their efforts on examining Web-based search queries for health behavior and medicine related topics. ${ }^{[17]}$ However, few were reported on the most cited articles and topics which were searched in Google Trends. Which author affiliations or regions searching health topics in Google Trends research are most prominent in the world are required to investigate.

As the use of Google Trends in examining human behavior is relatively novel, the search health topics of behaviors are constantly arising. Many topics have been examined, such as epilepsy, ${ }^{[18,19]}$ cancer, ${ }^{[20]}$ thrombosis, ${ }^{[21]}$ silicosis, ${ }^{[22]}$ and various medical procedures including cancer screening examinations, ${ }^{[23,24]}$ bariatric surgery, ${ }^{[25]}$ and laser eye surgery. ${ }^{[26]}$ We are thus interested in exploring (1) Which topics are most searched in healthcare; (2) which types of MESH terms are most characterized in Google Trends; (3) which articles are cited most in the past; (4) which regions in research affiliations are most in use of Google Trends in the world.

\section{Methods}

\subsection{Data Collection}

This review aimed to include all articles on the topics of health and medicine that have used Google Trends in the literature. We searched for the term "Google Trends" in article Title on PubMed ${ }^{[27]}$ since 2009, and following the Preferred Reporting Items for Systematic Reviews and Meta-Analyses guidelines, the total number of publications included in this review was 86 .

\subsection{Search in Pubmed}

First, we searched for the keyword "Google Trends" in the "Abstract-Title-Keywords" field for the journal articles. The first two articles using Google Trends were begun in 2009. The search returned 96 publications.

\subsection{Social network analysis and Pajek soft- ware}

Social network analysis (SNA) ${ }^{[28]}$ was applied to explore the pattern of entities in a system using the software of Pajek. ${ }^{[29]}$ In keeping with the Pajek guidelines, we defined an author (or paper keyword) as a node that is connected to other nodes through the edge (or say the relation). Usually, the weight between two nodes is defined by the number of connections.

Centrality is a vital index to analyze the network. Any individual or keyword lies in the center of the social net- work will determine its influence on the network and its speed to gain information. ${ }^{[30,31]}$

\subsection{Tasks to report the feature on health be- haviors in Google Trends research}

\subsubsection{What are the most number of author-defined keywords in the network}

Author-defined keywords were collected and analyzed using SNA to separate clusters. The most number of betweenness centrality in each cluster is presentative which is the most occurred frequency in the respective cluster.

\subsubsection{What are the most number of MESH terms in the network}

Similarly, the MESH terms were used to characterize the feature for each cluster, which is significantly different from the author-defined keywords and actually and objectively represents the feature clusters of articles using Google Trends. Furthermore, all articles were grouped into the respective MESH terms through the maximum likelihood method (MLM). That is, the highest score among MESH cluster is the one article belonged to. Whether the types of MESH clusters are different in the number of the citation will be examined using the one-way ANOVA. The article citations were retrieved from the Pubmed Central (PMC). The most cited articles will be reported in this study.

\subsubsection{What are the most number of citing jour- nals related to the searching topics in Google Trends research}

After retrieving the citing journals for articles from PMC, the association of journal citation can be analyzed using SNA. The most number of betweenness centrality were given to the journal representing the designated cluster of citing journals.

\subsubsection{What are the most influential research re- gions regarding health behavior using Google Trends}

The most influential research regions based on the order of author affiliations using the authorship-weighted scheme. ${ }^{[32]}$ That is, the first (i.e., primary) and the last (i.e., corresponding) authors gain higher weighted contributions to the given article. ${ }^{[33,34]}$ The visual display will be shown with a dashboard on Google Maps.

\subsection{Statistical tools and methods used in this study}

The Kendalls coefficient of concordance $(\mathrm{W})^{[35]}$ was computed to examine the internal consistency(IC) of the data(i.e., the four indices of $\mathrm{h}, \mathrm{g}, \mathrm{x}$, and $\mathrm{L}$ indexes as well as author impact factor (AIF) $)^{[36-41]}$ related to MeSH clusters. If the agreement is accepted by the statistical al- 
pha level $(<0.05),{ }^{[42]}$ the following analysis of one-way ANOVA for inspecting the difference in mean of indices is meaningful.

\section{Results}

\subsection{Task 1: the most number of author- defined keywords in the network}

Author-defined keywords displaying the top three representatives of clusters are Google trends, digital epidemiology, and infodemiology (Figure 1). It implies that many are methodology except for the only one topic of cosmetic surgery in the network.

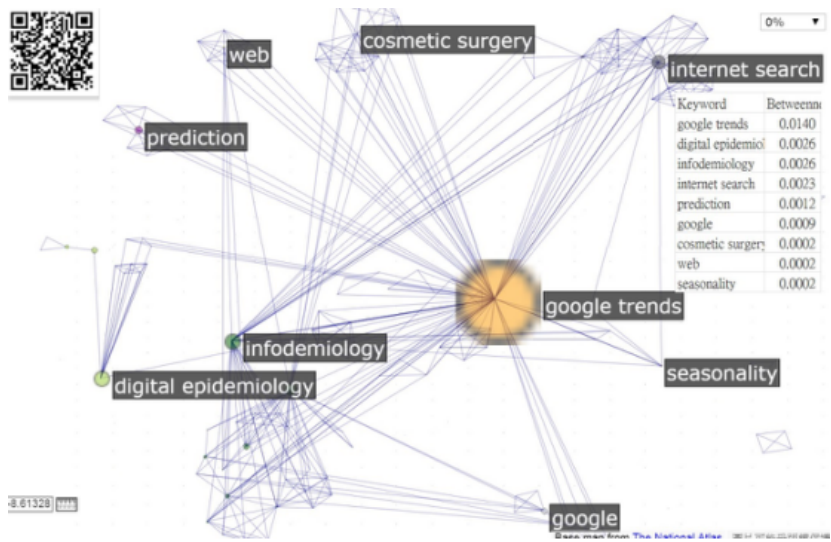

Figure 1. Author-defined keywords dispersed on a dashboard

\subsection{Task 2: the most number of MESH terms in the network}

As to the MESH terms, we see the MESH terms constituting the top five topics of the internet, trends, statistics \& numerical data, information seeking behavior, and web browser (Figure 2), which indicate that all articles regarding health behaviors in Google Trends can be formed by the five types of clusters.

The relevant bibliometric indices (i.e., the four of $h$, $\mathrm{g}, \mathrm{x}$, and $\mathrm{L}$ indexes as well as AIF) to the MESH clusters are closely associated with each other (i.e., having high correlation coefficients). The Kendalls $\mathrm{W}$ is 0.67 with three degrees of freedom $\left(\chi^{3}=12.05, \mathrm{p}=0.01\right)$, indicating data with acceptable internal consistency (IC). The MESH term represented by Internet earns the highest impact factor (IF) and presents significantly different among term clusters $(\mathrm{F}(3,20)=15.79, \mathrm{p}<0.001)$.

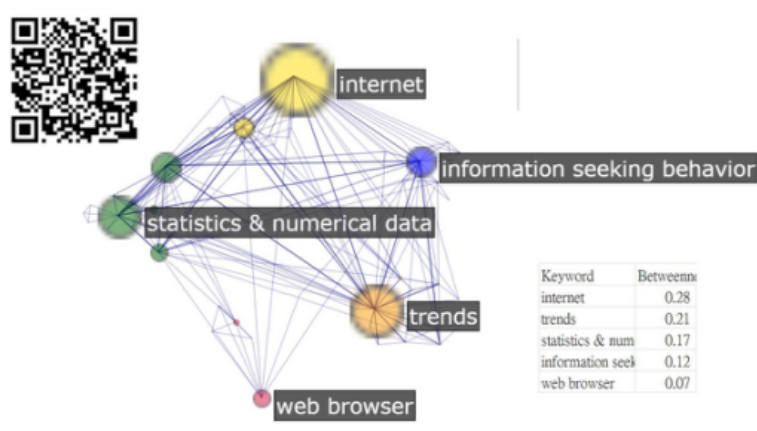

Figure 2. MESH terms dispersed on a dashboard

\subsection{Task 3: the most number of citing jour- nals}

The most number of citing journals is from PloS One (Figure 3) followed by the journals of JMIR Public Health Surveill and J Med Internet Res. The most cited articles are those from the US in 2009 (PMID= 19845471 cited 88 times) and the UK in 2013 (PMID= 23619126 cited 74 times). ${ }^{[43]}$

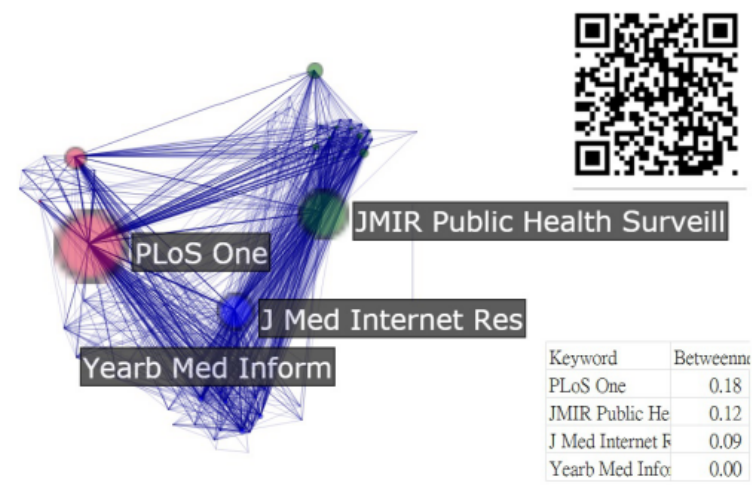

Figure 3. Clusters of citing journals related to the topic of health behaviors on Google trends

\subsection{Task 4: the most influential research re- gions}

The most number of author affiliations is from the US (Figure 4) followed by Italy and the UK as well as China, indicating the most influential research regions using Google Trends on healthcare are from the US, Europe, and China.

\section{Discussion}

This study found that (1) the most cited articles are those from the US in 2009 (PMID= 19845471 cited 88 times) and the UK in 2013 (PMID= 23619126 cited 


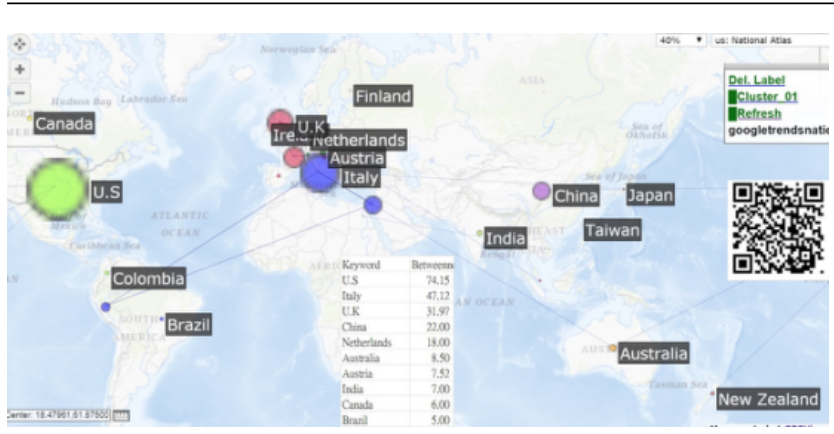

Figure 4. Distribution of author affiliations related to the topic of health behaviors on Google trends

74 times); (2) the MESH term represented by Internet earns the highest impact factor (IF) and presents significantly different among MESH clusters $(\mathrm{F}(3,20)=15.79$, $\mathrm{p}<0.001$ ); (3) the most number of citing journals is from PloS One; (4) the most number of author affiliations is from the US.

Referring the previous study ${ }^{[13]}$ which assessed the methods, tools, and statistical approaches in Google Trends Research, a total of $23.1 \%$ (24/104) studies used Google Trends data for examining seasonality, while $39.4 \%$ (41/104) and 32.7\% (34/104) used correlations and modeling, respectively. A few around $8.7 \%(9 / 104)$ used for predictions and forecasting in health-related topics. All the 104 examined papers but two included data visualization to present the study results. For instance, a worldwide map examined country for assessing health and medicine related issues and found that the US data have been employed in the most (60) studies, while other countries include the UK (15), Australia (13), Canada (9), Germany (8), and Italy (7). The results are somewhat different from the visualization of our study (i.e., the US, Italy, the UK and China has shown in Figure 4. It is because we emphasize the author collaboration instead of the regions applied by Google Trends.

Many studies have employed Google Trends for visualizing the changes of interest or discussing peaks and spikes, ${ }^{[44-47]}$ such as the search volumes for related terms, terms related to the studied topic, ${ }^{[48,49]}$ and the related internet searches. ${ }^{[50]}$ Others include the reporting of the polynomial trend lines and the investigating of statistically significant differences in yearly increases. ${ }^{[51]}$ Even Google Correlate has also been used to explore related terms, ${ }^{[52]}$ we have not found any applying authordefined keywords or MESH terms to visualize the related terms, as we show them in Figure 1 and Figure 2.

The vast majority of studies using Google Trends in health assessment have employed data visualization, such as figures, maps, or screenshots. The most popular way is correlating them with official data on dis- ease occurrence, spreading, and outbreaks. For instance, the assessment of suicide tendencies and (prescription or illegal) drug-related queries has been popular over the past years. However, the gap in the existing literature is the lack in use of Google Trends for predictions and forecasting in health-related topics which can benefit the general public by using and analyzing web-based data to provide insight to better assess health issues and topics in healthcare settings.

Finally, we particularly provided citation analysis to illustrated the most number of citing journals and proved that the MESH term of Internet earns the highest impact factor(IF) and presents significantly different among MESH clusters $(\mathrm{F}(3,20)=15.79, \mathrm{p}<0.001)$. Another feature in this study is about the usage of Kendalls coefficient of concordance (W) which told us the bibliometric indices closely related to each other in Table 1 , which is also rarely seen in the literature, particularly for data not following the normal distribution.

Table 1. Features of MESH clusters across bibliometric indices

\begin{tabular}{|c|c|c|c|c|c|c|c|c|}
\hline MESH cluster & Output & Cited number & IF & $\mathrm{h}$ & $\mathrm{g}$ & $\mathrm{x}$ & $\mathrm{L}$ & $\mathrm{Ag}$ \\
\hline internet & 20 & 374 & 18.7 & 9 & 13 & 14.14 & 19.34 & 28.62 \\
\hline trends & 11 & 33 & 3 & 5 & 5 & 5 & 5.74 & 6.2 \\
\hline statistics \& numerical data & 16 & 55 & 3.44 & 4 & 7 & 4.69 & 7.42 & 7.29 \\
\hline information seeking behavior & 2 & 2 & 1 & 4 & 7 & 1.41 & 1.41 & 7.29 \\
\hline web browser & 1 & 0 & 0 & & & & & \\
\hline Mean & 10 & 92.8 & 5.23 & 5.5 & 8 & 6.31 & 8.48 & 12.35 \\
\hline \multicolumn{9}{|l|}{ Correlation Coefficient } \\
\hline IF & & & 1 & & & & & \\
\hline $\mathrm{h}$ & & & 0.98 & 1 & & & & \\
\hline $\mathrm{g}$ & & & 0.94 & 0.89 & 1 & & & \\
\hline $\mathrm{x}$ & & & 0.98 & 0.97 & 0.87 & 1 & & \\
\hline $\mathrm{L}$ & & & 0.98 & 0.94 & 0.89 & 0.99 & 1 & \\
\hline $\mathrm{Ag}$ & & & 0.99 & 0.97 & 0.97 & 0.95 & 0.94 & 1 \\
\hline \multicolumn{9}{|l|}{ Kendall's consistence } \\
\hline W & 0.67 & & & & & & & \\
\hline$x^{3}$ & 12.05 & & & & & & & \\
\hline $\mathrm{df}$ & 3 & & & & & & & \\
\hline prob. & 0.01 & & & & & & & \\
\hline \multicolumn{9}{|c|}{ Cluster ANOVA: $\quad F(3,20)=15.79, p<0.001$} \\
\hline
\end{tabular}

\section{Limitations and Future study}

The interpretation and generalization of the conclusions should be cautious. First, the data were extracted from Medline. It is worth noting that any generalization should be made in similar fields of paper related contents.

Second, several studies have used other sources of big data, namely, Google News, ${ }^{[53-55,58]}$ Twitter, ${ }^{[56,57,59]}$ Yandex, ${ }^{[60]}$ Baidu, ${ }^{[61]}$ Wikipedia, Facebook and Google+, and YouTube. Even Google is the most popular search engine, other Web-based sources are used or even preferred to Google in some regions (e.g., in China) which is worthy of study in the future.

Third, although the data were carefully extracted from Medline and were professionally dealt with in every linkage, the originally downloaded contexts with some errors in symbols might affect the resulting reports. 
Fourth, there are many algorithms used for SNA. We just applied community cluster and betweenness centrality with weighted degrees in Figures. Any changes made with the specific algorithm will present different pattern and inference making.

Fifth, the social network analysis is not subject to the Pajeck software we used in this study, Others such as Ucinet $^{[62]}$ and Gephi ${ }^{[63]}$ are suggested to readers for use in the future.

\section{Conclusion}

This review consists of the studies published from 2009 to 2018 on Google Trends research in the PubMed databases based on the selected criteria. This review aimed to provide a point of reference for future research in health behaviors using Google Trends. Google Trends data are commonly used in infodemiology research and have been shown to empirically correlate with official health data in many topics. Using Google Trends become increasingly popular in health behavior assessment that can be crucial in monitoring and analyzing seasonal diseases as well as epidemics and outbreaks in healthcare settings.

\section{List of abbreviations}

AIF: author impact factor

BC: Betweenness centrality

IC: internal consistency

IF: impact factor

MESH: medical subject headings

PMC: Pubmed Central

SNA: Social network analysis

\section{Competing interests}

The authors declare that they have no competing interests.

\section{Authors contributions}

WC conceived and designed the study, TW performed the statistical analyses and were in charge of dealing with data. HY and TW helped design the study, collected information and interpreted data. WC monitored the research. All authors read and approved the final article.

\section{References}

[1] Al Nuaimi E, Al Neyadi H, Mohamed N, et al. Applications of big data to smart cities. Journal of Internet Services and Applications, 2015, 6(25): 1-15. https://doi.org/10.1186/s13174-015-0041-5
[2] Hilbert M and Lpez P. The world's technological capacity to store, communicate, and compute information. Science, 2011, 332(6025): 60-65. https://doi.org/10.1126/science.1200970

[3] Philip Chen CL and Zhang CY. Data-intensive applications, challenges, techniques and technologies: A survey on Big Data. Information Sciences, 2014, 275(10): 314-347. https://doi.org/10.1016/j.ins.2014.01.015

[4] Jin XL, Wah BW, Cheng X, et al. Significance and Challenges of Big Data Research. Big Data Research, 2015, 2(2): 59-64. https://doi.org/10.1016/j.bdr.2015.01.006

[5] Fosso Wamba S, Akter S, Edwards A, et al. How big data can make big impact: Findings from a systematic review and a longitudinal case study. International Journal of Production Economics, 2015, 165: 234-246. https://doi.org/10.1016/j.ijpe.2014.12.031

[6] Chang RM, Kauffman RJ and Kwon YO. Understanding the paradigm shift to computational social science in the presence of big data. Decision Support Systems, 2014, 63: 6780.

https://doi.org/10.1016/j.dss.2013.08.008

[7] Gandomi A and Haider M. Beyond the hype: Big data concepts, methods, and analytics. International Journal of Information Management, 2015, 35(2): 137-144. https://doi.org/10.1016/j.ijinfomgt.2014.10.007

[8] Hsu CF, Chien TW, Chow JC, et al. The most highlycited authors who published papers on the topic of health behavior: A Bibliometric Analysis. Adv Health Behavior,2018,1(1),24-29. https://doi.org/10.25082/AHB.2018.01.005

[9] Chien TW, Chen SH, Su SB, et al.A dashboard on Google Maps to show the most influential author on the topic of health behavior: A Bibliometric Analysis. Adv Health Behavior,2018, 1(1), 17-23. https://doi.org/10.25082/AHB.2018.01.004

[10] Burnap P, Rana OF, Avis N, et al. Detecting tension in online communities with computational Twitter analysis. Technological Forecasting and Social Change, 2015, 95: 96-108.

https://doi.org/10.1016/j.techfore.2013.04.013

[11] Google Trends. URL:https://trends.google.com/trends/ explore [accessed 2018-11-08]

[12] Scharkow M and Vogelgesang J. Measuring the Public Agenda using Search Engine Queries. International Journal of Public Opinion Research, 2011, 23(1): 104-113. https://doi.org/10.1093/ijpor/edq048

[13] Mavragani A, Ochoa1 G and Tsagarakis KP. Assessing the Methods, Tools, and Statistical Approaches in Google Trends Research: Systematic Review. Journal of Medical Internet Research, 2018, 20(11): e270. https://doi.org/10.2196/jmir.9366

[14] Fan JQ, Han F and Liu H. Challenges of Big Data Analysis. National Science Review, 2014, 1(2): 293-314. https://doi.org/10.1093/nsr/nwt032

[15] Yoo C, Ramirez L and Liuzzi J. Big data analysis using modern statistical and machine learning methods in medicine. International Neurourology Journal, 2014, 18(2): 50-57.

https://doi.org/10.5213/inj.2014.18.2.50 
[16] Gu D, Li J, Li X, et al. Visualizing the knowledge structure and evolution of big data research in healthcare informatics. Int J Med Inform, 2017, 98: 22-32. https://doi.org/10.1016/j.ijmedinf.2016.11.006

[17] Nuti SV, Wayda B, Ranasinghe I, et al. The use of google trends in health care research: a systematic review. PLoS One, 2014, 9(10): e109583. https://doi.org/10.1371/journal.pone.0109583

[18] Brigo F, Igwe SC, Ausserer H, et al. Why do people Google epilepsy? An infodemiological study of online behavior for epilepsy-related search terms. Epilepsy and Behavior, 2014, 31: $67-70$. https://doi.org/10.1016/j.yebeh.2013.11.020

[19] Brigo F and Trinka E. Google search behavior for status epilepticus. Epilepsy Behav, 2015, 49: 146-149. https://doi.org/10.1016/j.yebeh.2015.02.029

[20] Murray G, O'Rourke C, Hogan J, et al. Detecting internet search activity for mouth cancer in Ireland. British Journal of Oral and Maxillofacial Surgery, 2016, 54(2): 163-165. https://doi.org/10.1016/j.bjoms.2015.12.005

[21] Scheres LJ, Lijfering WM, Middeldorp S, et al. Influence of World Thrombosis Day on digital information seeking on venous thrombosis: a Google Trends study. J Thromb Haemost, 2016, 14(12): 2325-2328. https://doi.org/10.1111/jth.13529.Epub2016Nov19

[22] Bragazzi NL, Dini G, Toletone A, et al. Leveraging Big Data for Exploring Occupational Diseases-Related Interest at the Level of Scientific Community, Media Coverage and Novel Data Streams: The Example of Silicosis as a Pilot Study. PLoS One, 2016,11(11): e0166051. https://doi.org/10.1371/journal.pone.0166051

[23] Rosenkrantz AB and Prabhu V. Public Interest in ImagingBased Cancer Screening Examinations in the United States: Analysis Using a Web-Based Search Tool. American Journal Roentgenology, 2016, 206(1): 113-118. https://doi.org/10.2214/AJR.15.14840

[24] Schootman M, Toor A, Cavazos-Rehg P, et al. The utility of Google Trends data to examine interest in cancer screening. BMJ Open, 2015, 5(6): e006678. http://dx.doi.org/10.1136/bmjopen-2014-006678

[25] Stein JD, Childers DM, Nan B, et al. Gauging interest of the general public in laser-assisted in situ keratomileusis eye surgery. Cornea, 2013, 32(7): 1015-1018. https://doi.org/10.1097/ICO.0b013e318283c85a

[26] PubMed. accessed 18/4/2018. URL: https://www.ncbi.nlm. nih.gov/pubmed/ [accessed 2018-09-07]

[27] Bright CF, Haynes EE, Patterson D, et al. The Value of Social Network Analysis for Evaluating AcademicCommunity Partnerships and Collaborations for Social Determinants of Health Research. Ethn Dis. 2017, 27(Suppl 1): 337-346. https://doi.org/10.18865/ed.27.S1.337.eCollection2017

[28] De Nooy W, Mrvar A and Batagelj V. Exploratory Social Network Analysis With Pajek: Revised and Expanded, 2nd edn. New York, NY: Cambridge University Press, 2011. http://assets.cambridge.org/97811070/02388/frontmatter/ 9781107002388_frontmatter.pdf

[29] Otte E and Rousseau R. Social network analysis: a powerful strategy, also for the information sciences. Journal of Information Science, 2002, 28(6): 441453. https://doi.org/10.1177/016555150202800601
[30] Phan TG, Beare R, Chen J, et al. Googling Service Boundaries for Endovascular Clot Retrieval Hub Hospitals in a Metropolitan Setting: Proof-of-Concept Study. Stroke, 2017, 48(5): 1353-1361. https://doi.org/10.1161/STROKEAHA.116.015323

[31] Hsu CF, Chien TW, Chow JC, et al. The most highly-cited authors who published papers on the topic of health behavior: A Bibliometric Analysis. Advance in Health And Behavior, 2018, 1(1): 1-6. https://doi.org/10.25082/AHB.2018.01.005

[32] Chien TW, Wang HY, Chang Y, et al. Using Google Maps to display the pattern of coauthor collaborations on the topic of schizophrenia: A systematic review between 1937 and 2017. Schizophr Res. 2018, S0920-9964(18): 30573-30575. https://doi.org/10.1016/j.schres.2018.09.015

[33] Chien TW, Chow JC, Chang Y, et al. Applying Gini coefficient to evaluate the author research domains associated with the ordering of author names: A bibliometric study. Medicine, 2018, 97(39): e12418. https://doi.org/10.1097/MD.0000000000012418

[34] Kendall MG and Babington SB. The Problem of m Rankings. The Annals of Mathematical Statistics, 1939, 10(3): 275287. https://doi.org/10.1214/aoms/1177732186

[35] Hirsch JE. An index to quantify an individual's scientific research output. Proc Natl Acad Sci USA, 2005, 102(46): 16569-16572. https://doi.org/10.1073/pnas.0507655102

[36] Egghe L. Theory and practise of the g-index. Scientometrics, 2006, 69(1): 131-152. https://doi.org/10.1007/s11192-006-0144-7

[37] Fenner T, Harris M, Levene M, et al. A novel bibliometric index with a simple geometric interpretation. PLoS One, 2018, 13(7): e0200098. https://doi.org/10.1371/journal.pone.0200098

[38] Belikov AV and Belikov VV. A citation-based, authorand age-normalized, logarithmic index for evaluation of individual researchers independently of publication counts. F1000Research, 2015, 4: 884. https://doi.org/10.12688/f1000research.7070.1

[39] Lippi G and Mattiuzzi C.Scientist impact factor (SIF): a new metric for improving scientists' evaluation? Ann Transl Med. 2017, 5(15): 303. https://doi.org/10.21037/atm.2017.06.24

[40] Pan RK and Fortunato S. Author Impact Factor: tracking the dynamics of individual scientific impact. Scientific Reports, 2014, 4: 4880. https://doi.org/10.1038/srep04880

[41] Zaiontz C. Kendalls Coefficient of Concordance (W). Real Statistics Using Excel at http://www.real-statistics.com/ reliability/kendalls-w/

[42] Carneiro HA and Mylonakis E. Google trends: a web-based tool for real-time surveillance of disease outbreaks. Clin Infect Dis. 2009, 49(10): 1557-1564. https://doi.org/10.1086/630200

[43] Kostkova P, Fowler D, Wiseman S, et al. Major infection events over 5 years: how is media coverage influencing online information needs of health care professionals and the public? J Med Internet Res. 2013, 15(7): e107. https://doi.org/10.2196/jmir.2146 
[44] Brigo F, Lochner P, Tezzon F, et al. Web search behavior for multiple sclerosis: An infodemiological study. Multiple Sclerosis and Related Disorders, 2014, 3(4): 440-443. https://doi.org/10.1016/j.msard.2014.02.005

[45] Jha S, Wang Z, Laucis N, et al. Trends in Media Reports, Oral Bisphosphonate Prescriptions, and Hip Fractures 19962012: An Ecological Analysis. J Bone Miner Res. 2015, 30(12): 2179-2187. https://doi.org/10.1002/jbmr.2565

[46] Lawson MAC, Lawson MA, Kalff R, et al. Google Search Queries About Neurosurgical Topics: Are They a Suitable Guide for Neurosurgeons? World Neurosurg, 2016, 90: 179-185. https://doi.org/10.1016/j.wneu.2016.02.045

[47] Chaves JN, Libardi AL, Agostinho-Pesse RS, et al. Telehealth: assessment of websites on newborn hearing screening in Portuguese Language. CoDAS, 2015, 27(6): 526-533. http://dx.doi.org/10.1590/2317-1782/20152014169

[48] Luckett T, Disler R, Hosie A, et al. Content and quality of websites supporting self-management of chronic breathlessness in advanced illness: a systematic review. NPJ Prim Care Respir Med. 2016, 26: 16025. https://doi.org/10.1038/npjpcrm.2016.25

[49] Davis NF, Gnanappiragasam S abd Thornhill JA. Interstitial cystitis/painful bladder syndrome: the influence of modern diagnostic criteria on epidemiology and on Internet search activity by the public. Transl Androl Urol. 2015, 4(5): 506511. https://doi.org/10.3978/j.issn.2223-4683.2015.06.08

[50] Linkov F, Bovbjerg DH, Freese KE, et al. Bariatric surgery interest around the world: what Google Trends can teach us. Surg Obes Relat Dis. 2014, 10(3): 533-538. https://doi.org/10.1016/j.soard.2013.10.007

[51] Harsha AK, Schmitt JE and Stavropoulos SW. Match day: online search trends reflect growing interest in IR training. J Vasc Interv Radiol. 2015, 26(1): 95-100. https://doi.org/10.1016/j.jvir.2014.09.011

[52] Pollett S, Wood N, Boscardin WJ, et al. Validating the Use of Google Trends to Enhance Pertussis Surveillance in California. PLoS Curr. 2015, 19: 1-10. https://doi.org/10.1371/currents.outbreaks. 7119696b3e7523faa4543faac87c56c2

[53] Sentana-Lledo D, Barbu CM, Ngo MN, et al. Seasons, Searches, and Intentions: What The Internet Can Tell Us About The Bed Bug (Hemiptera: Cimicidae) Epidemic. J Med Entomol. 2016, 53(1): 116-121. https://doi.org/10.1093/jme/tjv158
[54] Solano P, Ustulin M, Pizzorno E, et al. A Google-based approach for monitoring suicide risk. Psychiatry Res. 2016, 246: $581-586$. https://doi.org/10.1016/j.psychres.2016.10.030

[55] Bragazzi NL, Dini G, Toletone A, et al. Leveraging Big Data for Exploring Occupational Diseases-Related Interest at the Level of Scientific Community, Media Coverage and Novel Data Streams: The Example of Silicosis as a Pilot Study. PLoS One, 2016, 11(11): e0166051. https://doi.org/10.1371/journal.pone.0166051

[56] Huesch MD, Currid-Halkett E and Doctor JN. Public hospital quality report awareness: evidence from National and Californian Internet searches and social media mentions, 2012. BMJ Open, 2014, 4(3): e004417. https://doi.org/10.1136/bmjopen-2013-004417

[57] Pandey A, Abdullah K and Drazner MH. Impact of Vice President Cheney on public interest in left ventricular assist devices and heart transplantation. Am J Cardiol. 2014, 113(9): 1529-1531. https://doi.org/10.1016/j.amjcard.2014.02.007

[58] Bragazzi NL, Watad A, Brigo F, et al. Public health awareness of autoimmune diseases after the death of a celebrity. Clincal Rheumatology, 2016, 36(8): 1911-1917. https://doi.org/10.1007/s10067-016-3513-5

[59] Cha Y and Stow CA. Mining web-based data to assess public response to environmental events. Environmental Pollution, 2015, 198: 97-99. https://doi.org/10.1016/j.envpol.2014.12.027

[60] Zheluk A, Quinn C and Meylakhs P. Internet search and krokodil in the Russian Federation: an infoveillance study. J Med Internet Res. 2014, 16(9): e212. https://doi.org/10.2196/jmir.3203

[61] Huang J, Zheng R and Emery S. Assessing the impact of the national smoking ban in indoor public places in china: evidence from quit smoking related online searches. PLoS One, 201, 8(6): e65577. https://doi.org/10.1371/journal.pone.0065577

[62] Borgatti SP, Everett MG and Freeman LC. Ucinet for Windows: Software for Social Network Analysis. Harvard, MA: Analytic Technologies, 2002.

[63] Bastian M, Heymann S, Jacomy M. Gephi: an open source software for exploring and manipulating networks. International AAAI Conference on Weblogs and Social Media,2009. 